\title{
The earliest electrocardiographic evidence of myocardial infarction
}

\author{
David Short \\ From The Royal Infirmary, Aberdeen
}

The earliest cardiograms recorded in 150 episodes of slight or subacute infarction have been analysed. In only 27 (18\%) did the tracing show a pattern regarded as diagnostic of acute infarction, i.e. localized $S T$ elevation of $1 \mathrm{~mm}$. or more. A further $72(48 \%)$ showed a major abnormality of coronary type not diagnostic of recent infarction. Ten showed a pattern of left ventricular hypertrophy.

In 4 I episodes (27\%) the initial cardiogram showed no abnormality classified under the Minnesota Code; 24 of these showed minor abnormalities, 7 were borderline, and 10 were within normal limits. Of the minor abnormalities, the most frequent was horizontal or 'ischaemic' $S T$ depression of less than $0.5 \mathrm{~mm}$., often in association with low $T$ waves. Very low $T$ waves were the main feature in a further 5 cases.

The most important minor abnormality was a slight degree of ST elevation. This was present without any major abnormality in 5 cases. In a further 12 cases it was associated with a major abnormality. Its importance lies in the fact that it points not merely to infarction but to acute infarction. Minor ST elevation assumes a variety of patterns which are described and illustrated.

The fact that the initial cardiogram was normal or borderline in over $10 \%$ of episodes is a reminder of the danger of attempting to make a diagnosis of myocardial infarction on the cardiogram alone.

The early diagnosis of slight and subacute coronary attacks is one of the major problems in the management of acute coronary heart disease at the present time. Such attacks present great difficulties to the family doctor confronted by a patient with atypical chest pain in his home or in the consulting room; but they also sometimes present an insoluble problem to the hospital doctor with all the latest diagnostic aids at his disposal. In spite of the advances in enzymology and other methods of investigation, electrocardiography retains the pre-eminent place in diagnosis. The electrocardiogram of major acute infarction is well recognized, and Evans and his co-workers (Evans and McRae, 1952; Evans, 1965) have emphasized the various minor abnormalities which may be found in small healed infarcts, but the earliest changes seen in small acute infarcts are poorly documented and frequently unrecognized.

\section{Subjects and methods}

This study presents an analysis of the first cardiogram recorded in 150 episodes of acute or subacute myocardial infarction in 142 patients. Eight patients were studied in two episodes. These patients were part of a series of over 400 Received 21 July 1969. patients seen in consultation at the request of the patient's family physician on account of a suspected coronary attack. In none was the patient shocked or regarded by the doctor as ill enough to warrant urgent hospital admission, and in only a very few was an immediate visit requested; in the majority the consultation was undertaken within 48 hours. Eighty per cent were seen in their homes; the remainder were regarded as fit enough for an appointment at the Out-patient Clinic or private consulting room. The criteria on which the diagnosis of acute infarction was based are given in Table $\mathrm{I}$.

Of the 142 patients, 9I (64\%) were men; 16 per cent were under 50 years of age, 56 per cent between 50-69, and 28 per cent 70 years of age or older. In $39(26 \%)$ episodes there was a history of previous proven myocardial infarction.

The interval between the onset of symptoms of acute infarction and the recording of the first cardiogram was less than 12 hours in 27 episodes, 12-24 hours in 25, I-3 days in 30, 4-7 days in $28,7-14$ days in 20, and over 14 days in 20 .

The cardiogram was recorded on a direct writing Cambridge Transrite Mark II or III machine at a paper speed of $25 \mathrm{~mm}$. per sec. Twelve leads were recorded routinely; the three standard bipolar leads, the three unipolar leads, and six praecordial V leads. Leads III and aVF were re-recorded in full inspiration in cases where there was a doubtful $Q, S T$, or $T$ wave abnormality in these leads. In cases where the diagnosis 
was already obvious leads $V_{3}$ and $V_{5}$ were sometimes omitted. Occasionally a second set of praecordial leads was recorded at a higher level. An effort test was never performed because of its danger in patients with recent myocardial infarction. An aspartate transaminase (SGOT) and alanine transaminase (SGPT) estimation was made in cases seen within 72 hours of the onset if the clinical and cardiographic evidence was inconclusive.

A working diagnosis was made at the time of consultation on the evidence available (including in some cases previous cardiograms) and this formed the basis of the immediate management. The majority of patients diagnosed confidently as acute or subacute myocardial infarction were admitted to hospital, as also were many of those in whom this diagnosis seemed probable. All patients in these two categories, as well as those regarded as doubtful, had further cardiograms and when appropriate repeated serum enzyme estimations. In the event of death, a necropsy was requested and special attention was directed to the state of the heart. At the conclusion of the illness, the evidence was reviewed and a final diagnosis was made.

The cardiograms were analysed primarily on the basis of the Minnesota Code (Blackburn et al., 1960). Tracings showing no codifiable abnormality were further subdivided into those showing the lesser signs of restricted myocardial infarction described by Evans (1965), a borderline group, and those with no detectable abnormality (Table 2).

Particular attention was paid to minor degrees of ST elevation, ST depression, and $T$ wave abnormalities. The Minnesota Code does not recognize ST elevation of less than $\mathrm{I} \cdot 0 \mathrm{~mm}$. as abnormal. In the present study, definite ST elevation of less than I mm. (in leads other than VI-4) has been recorded as a minor abnormality. Similarly, the Minnesota Code does not recognize ST depression of less than $0.5 \mathrm{~mm}$., though Evans regards the slightest degree of horizontal or 'plane' depression as important. In this study four grades have been employed; I - borderline; 2 - definite depression of less than $0.5 \mathrm{~mm}$; 3 -depression of $0.5-1.0 \mathrm{~mm}$.; 4 - depression of I $\mathrm{mm}$. or more. Tracings were placed in the borderline group if there was slight horizontal ST depression associated with tachycardia, or if the depression was of the upward sloping $(\mathrm{J})$ type. Minor T wave abnormalities were difficult to evaluate because $T$ wave voltage varies so greatly from one individual to another. The Minnesota Code does not recognize low $T$ waves as abnormal; but Evans does, though without defining them. In this study, a $T$ wave less than Io per cent of the height of the $R$ wave in one or more leads in which the $T$ wave is normally positive has been accepted as a minor abnormality. $T$ waves which appeared low but were not low enough to qualify as a minor abnormality were placed in the borderline group. Other changes qualifying for the borderline group were the presence of a QS wave in leads III and aVF without other supporting evidence
TABLE I Criteria on which the diagnosis of acute infarction was based

No. of

cases

A Major ST segment elevation (not necessarily in first cardiogram) with classical evolution

B Abnormal $Q$ waves together with serial $S T$ and/or $\mathrm{T}$ wave abnormalities

C Diagnostic serum enzyme pattern in association with cardiographic changes or cardiac pain at rest or both

D Serial ST and T wave changes of coronary type associated with either cardiac pain at rest or effort angina of recent onset or crescendo type

E Miscellaneous

Three patients with effort angina culminating in prolonged cardiac pain at rest who had abnormal cardiograms consistent with myocardial infarction but without serial changes

Two patients presenting with atypical symptoms and cardiograms in whom diagnosis was confirmed at necropsy

Total 150

TABLE 2 Criteria for classification of

electrocardiograms

\begin{tabular}{lll}
\hline Group & Description & Category in Minnesota Code \\
\hline I & ST segment elevation I mm. or more & IV. 4 \\
2 & Abnormal Q waves & I. I \\
3 & T wave inverted, flat, or diphasic & V. I-3 \\
4 & ST segment depression 0.5 mm. or & IV. I-3 \\
greater & III. I (together with ST/T \\
abnormality in LV & leads)
\end{tabular}

of myocardial infarction, an $S$ greater than $R$ in lead II, with no $S$ wave in lead I, and conspicuous splintering of the QRS complex, or a partial bundle-branch block pattern.

\section{Results}

An analysis of the abnormalities found in the initial cardiogram is given in Table 3 , and a correlation between these changes and the interval between the onset of symptoms of infarction and the recording of the cardiogram is shown in Table 4.

\section{(a) Major Abnormalities}

$S T$ elevation of I $\mathrm{mm}$. or more-the hallmark of acute infarction-was seen in the initial cardiogram in 27 episodes. In 7 more major ST elevation was not present in the first 
TAB LE 3 Analysis of earliest cardiographic pattern in 150 episodes of infarction (Cases with previous infarction in brackets)

\begin{tabular}{llcc}
\hline Group & ECG Pattern & Total & Per cent \\
\hline I & ST elevation & $27(3)$ & 18 \\
2 & Q waves & $16(5)$ & 11 \\
3 & T inverted, flat, or & $35(14)$ & 23 \\
& $\quad$ diphasic & & \\
4 & ST depression & $21(6)$ & 14 \\
5 & Left ventricular & I0 (6) & 6.5 \\
6 & $\quad$ hypertrophy & & \\
7 & Miscellaneous & $0(0)$ & 0 \\
8 & Morderline & $24(3)$ & 16 \\
9 & Normal & $7(1)$ & 5 \\
\hline & & $10(1)$ & 6.5 \\
\hline
\end{tabular}

tracing but developed later. ST elevation of less than $1 \mathrm{~mm}$. was seen in 17 patients, but this group is considered in detail in the section on minor abnormalities.

Abnormal $Q$ waves-the hallmark of transmural infarction-were seen in the initial cardiogram in 16 episodes, always in association with ST and/or $T$ wave abnormalities. Five of these patients were known to have had a previous infarction, and in these the $Q$ waves might have been a legacy from this earlier episode. In a further 40 patients, $Q$ waves developed in a later tracing.

Inverted, flat, or diphasic $T$ waves These were seen in the initial cardiogram in 35 episodes. A frequent early abnormality was slight inversion of the terminal portion of the wave (see Fig. 9). $T$ wave abnormalities were often associated with ST depression, and some patients with ST depression in the initial cardiogram developed $T$ inversion in later tracings.
ST segment depression A depression of $0.5 \mathrm{~mm}$. or more was seen in the initial cardiogram in 21 episodes, usually in association with a reduction in $T$ wave voltage, and often followed by $\mathrm{T}$ wave inversion.

Left ventricular hypertrophy pattern In 10 episodes, the initial cardiogram showed a pattern entirely consistent with left ventricular hypertrophy, i.e. ST and/or $T$ wave abnormalities confined to the lateral leads, associated with left axis deviation or increased QRS voltage (Fig. I).

\section{(b) Minor abnormalities}

In $4 \mathrm{I}$ episodes the initial cardiogram showed no abnormality codifiable under the Minnesota Code, but in 24 of these the tracing was nevertheless recognizably abnormal. The most frequent minor abnormalities were ST elevation, ST depression, and reduction in $T$ wave voltage. Each of these patterns demands separate consideration.

Minor ST elevation was the most prominent abnormality in five episodes. In two cases it was the sole abnormality (Fig. 2), and in three it was associated with a minor degree of $\mathrm{T}$ wave flattening or ST depression. In a further 12 episodes, minor ST elevation was found in association with a major abnormality, and in these cases its presence was of the greatest value as evidence that infarction was recent.

Two main patterns of ST elevation were seen. The more frequent and distinctive was a slight upward convexity or 'humping' of the ST segment (Fig. 3). In its earliest stage, this amounted to no more than a loss of the

TABLE 4 Correlation between initial cardiogram and interval from onset of symptoms of infarction

(Cases with previous infarction in brackets)

\begin{tabular}{|c|c|c|c|c|c|c|c|c|}
\hline \multirow[t]{2}{*}{ Group } & \multirow[t]{2}{*}{ ECG pattern } & \multicolumn{6}{|c|}{ Interval } & \multirow[t]{2}{*}{ Total } \\
\hline & & $\begin{array}{l}<12 \\
\text { hours }\end{array}$ & $\begin{array}{l}\text { 12-24 } \\
\text { hours }\end{array}$ & $\begin{array}{l}1-3 \\
\text { days }\end{array}$ & $\begin{array}{l}4-7 \\
\text { days }\end{array}$ & $\begin{array}{l}7-14 \\
\text { days }\end{array}$ & $\begin{array}{l}>14 \\
\text { days }\end{array}$ & \\
\hline $\begin{array}{l}\text { I } \\
2 \\
3\end{array}$ & $\begin{array}{l}\text { ST elevation } \\
Q \text { waves } \\
T \text { waves inverted, } \\
\text { flat, or diphasic }\end{array}$ & $\begin{array}{l}5 \\
4(1) \\
7(4)\end{array}$ & $\begin{array}{l}6 \\
3(1) \\
6(1)\end{array}$ & $\begin{array}{l}5(2) \\
2 \\
8(4)\end{array}$ & $\begin{array}{l}6 \\
3(1) \\
4(2)\end{array}$ & $\begin{array}{l}4 \\
0 \\
6(3)\end{array}$ & $\begin{array}{l}1(I) \\
4(2) \\
4\end{array}$ & $\begin{array}{l}27(3) \\
16(5) \\
35(14)\end{array}$ \\
\hline $\begin{array}{l}4 \\
5 \\
6 \\
7 \\
8 \\
9\end{array}$ & $\begin{array}{l}\text { ST depression } \\
\text { Left ventricular hypertrophy } \\
\text { Miscellaneous } \\
\text { Minor abnormalities } \\
\text { Borderline } \\
\text { Normal }\end{array}$ & $\begin{array}{l}3(1) \\
3(1) \\
0 \\
3 \\
1 \\
1\end{array}$ & $\begin{array}{l}4(I) \\
1(I) \\
0 \\
4(I) \\
0 \\
1\end{array}$ & $\begin{array}{l}4(1) \\
2(1) \\
0 \\
5 \\
3(1) \\
1\end{array}$ & $\begin{array}{l}4(2) \\
1(1) \\
0 \\
4 \\
2 \\
4\end{array}$ & $\begin{array}{l}3(1) \\
2(2) \\
0 \\
3 \\
0 \\
2\end{array}$ & $\begin{array}{l}3 \\
1 \\
0 \\
5(2) \\
1 \\
1(1)\end{array}$ & $\begin{array}{l}21(6) \\
10(6) \\
0 \\
24(3) \\
7(1) \\
10(1)\end{array}$ \\
\hline & Total & $27(7)$ & $25(5)$ & $30(9)$ & $28(6)$ & $20(6)$ & $20(6)$ & I 50 (39) \\
\hline
\end{tabular}




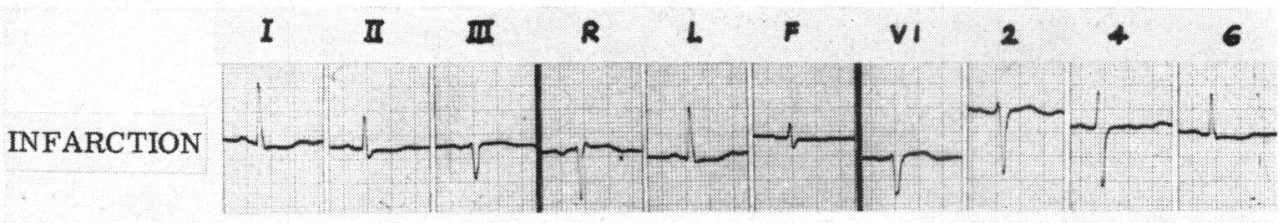

Rate $75 / \mathrm{min}$.

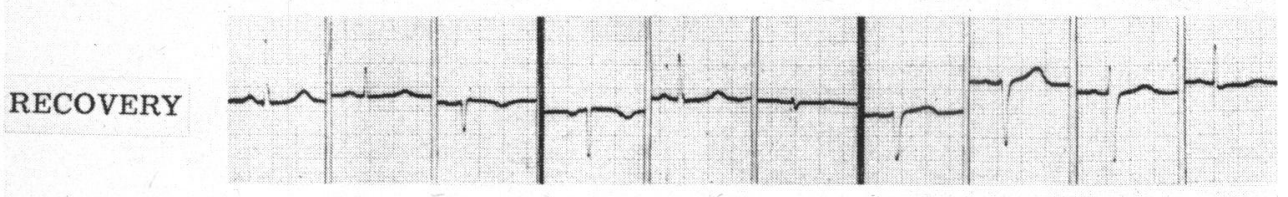

Rate 55/min.

FIG. I Left ventricular hypertrophy pattern.

Case W. G., a woman aged 5I, known hypertensive. Infarction: pattern consistent with left ventricular hypertrophy. BP $180 / 100 \mathrm{~mm}$. Hg. Recovery: Three months later, considerable cardiographic recovery in spite of a higher blood pressure - now 230/125 mm. Hg. Evolution consistent with myocardial infarction. ( $\times$ approx. one half natural size.) In this and all subsequent figures, the thicker vertical lines indicate $0.2 \mathrm{sec}$. intervals, and the thicker horizontal lines $0.5 \mathrm{mV}$.

FIG. 2 Minor ST segment elevation.

Case A. M., a man aged 53; no relevant previous history. Early infarction: first attack of cardiac pain three days previously; second attack six hours before cardiogram. Tracing shows less than $0.5 \mathrm{~mm}$. ST elevation in I (see magnified cardiogram, Fig. 4). Later: Next day, loss of normal upward concavity of $S T$ in I, with reduction in $T$ voltage in this lead. Similar changes in V6. $T$ inverted in $a V L$ and diphasic in $V 5$.

Maximal abnormality: Nine days later $T$ inverted in $I, a V L$, and $V 4-6$.

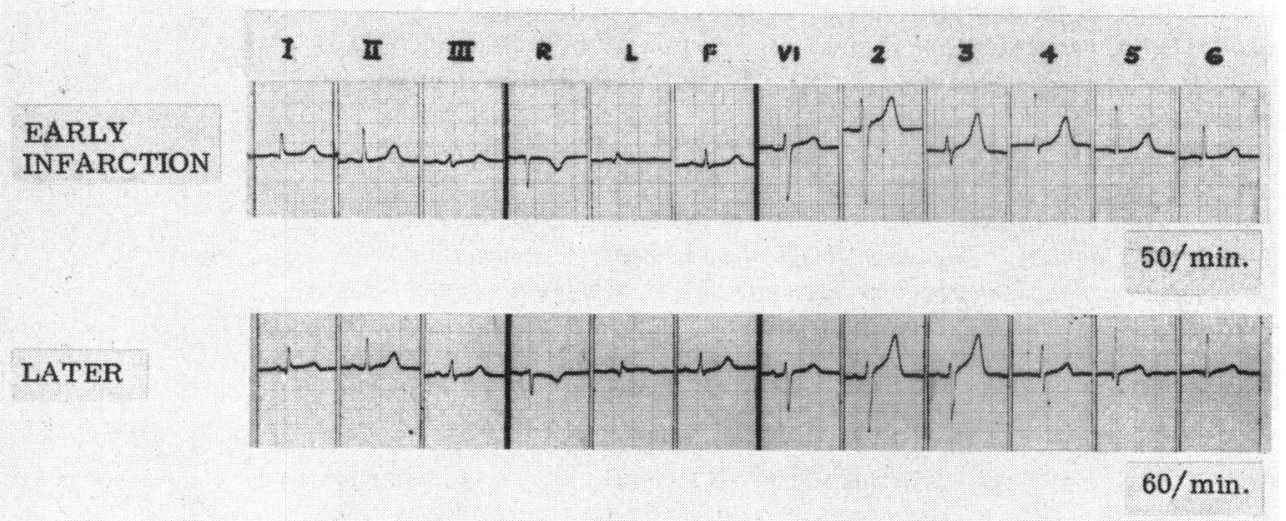

MAXIMAL ABNORMALITY

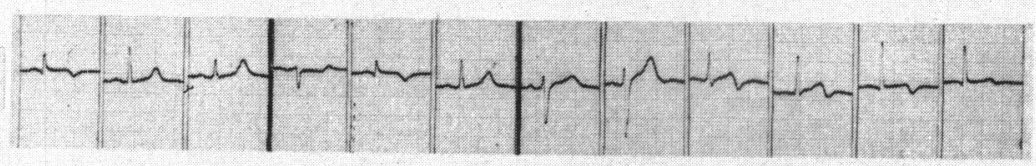

$60 / \mathrm{min}$. 


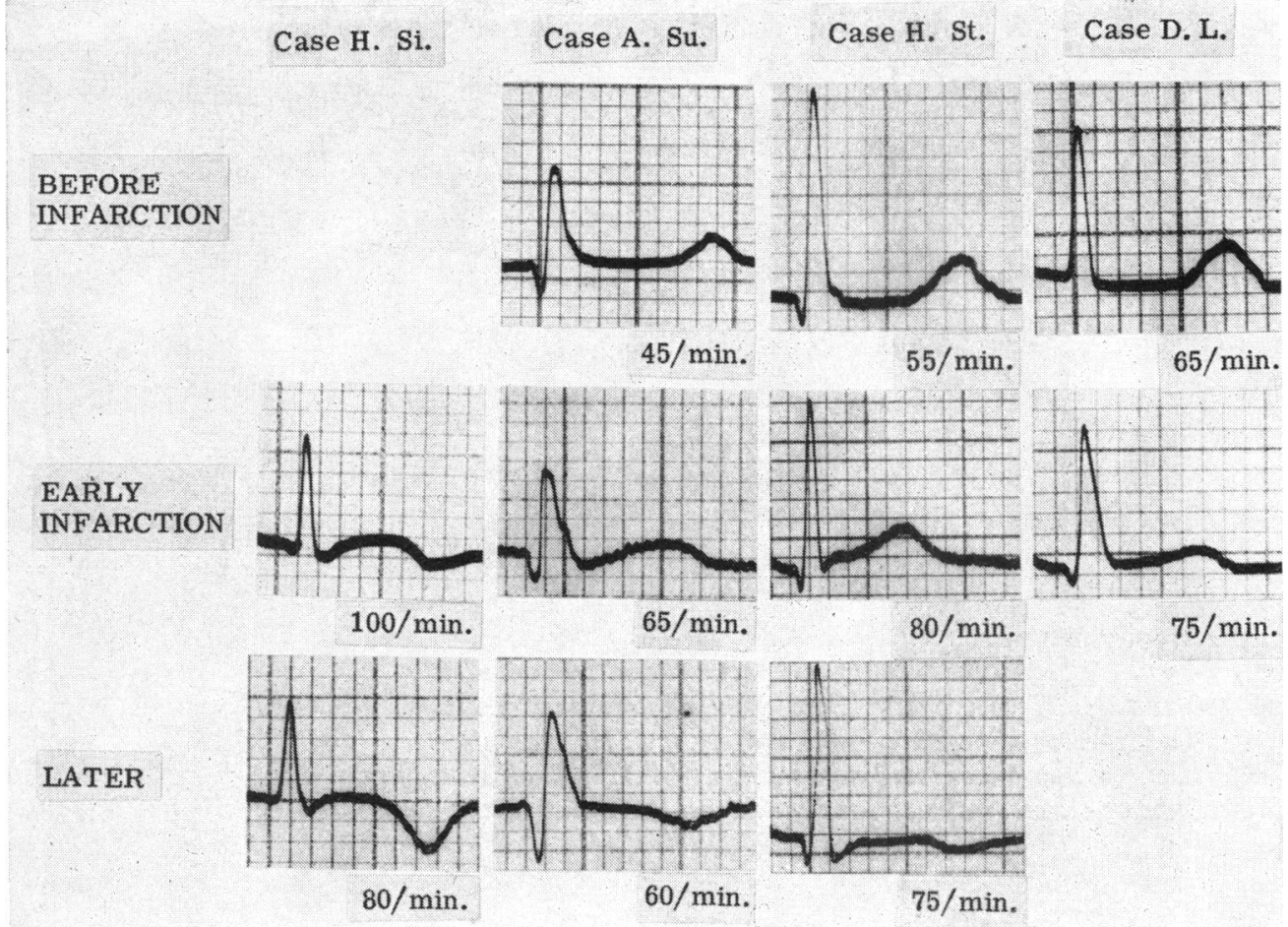

FIG. 3 Minor ST segment elevation - convex or 'humped' type.

Case H. Si., a man aged $5 I$ (lead V6). Three days after onset of cardiac pain, the ST segment, though not appreciably elevated, was strikingly 'humped'. Similar, though less conspicuous, changes were present in leads II, III, aVF, and V5. The T wave was flat in I. Three weeks later, the $T$ wave had become inverted in V6, and also in leads II, III, aVF, and V5.

Case A. Su., a woman, aged 66 (lead aVL). One year before infarction, the cardiogram showed only left axis deviation and grade $I$ (i.e. borderline) ST depression. Four hours after the onset of infarction, the upward concavity of the ST segment was replaced by a slight convexity. A similar deformity was seen in lead I, and there was also grade $2 S T$ depression in VI to 5.

Case H. St., a man, aged 58 (lead I). Eight months before infarction, there was grade $2 S T$ depression in leads I, II, and V6 only, persisting from a previous known small infarct. Three days after the onset of infarction, there was a loss of the normal upward concavity of the ST segment. Minor ST elevation was also seen in leads II, aVL, and V6.

Case D. L., a woman, aged 60 (lead V6). Two years before infarction, the cardiogram showed $Q S$ waves in leads $V_{2}$ and $V_{3}$, and grade $2 S T$ depression in leads I and V6 persisting after a previous infarction. During this second infarction, there was a loss of the normal ST concavity associated with a reduction in $T$ wave voltage. (The onset of this episode of infarction could not be accurately dated. The history suggested that it might have been one day or possibly one week before the cardiogram was recorded.)

In the three cases in which previous cardiograms were available, there was an apparent shortening of the $Q T$ interval during infarction.

normal upward concavity of the ST segment. This was usually associated with a reduction in $T$ wave voltage and apparent shortening of the QT interval.

The other form of ST elevation was the concave or 'saddle-shaped' variety (Fig. 4). This is less specific than the convex type since it is sometimes seen in health. In acute infarction, however, serial cardiograms show characteristic ST and $T$ wave changes, whereas in health the pattern remains more or less constant for months or years.

Minor ST depression, with or without reduction in $T$ wave voltage, was the only abnormality in the initial cardiogram in 14 episodes (Fig. 5 and 6). In its slightest degree, it amounted to no more than a prolongation 


\section{Case J.E. Case J.MacF. Case A.M. NORMAL}

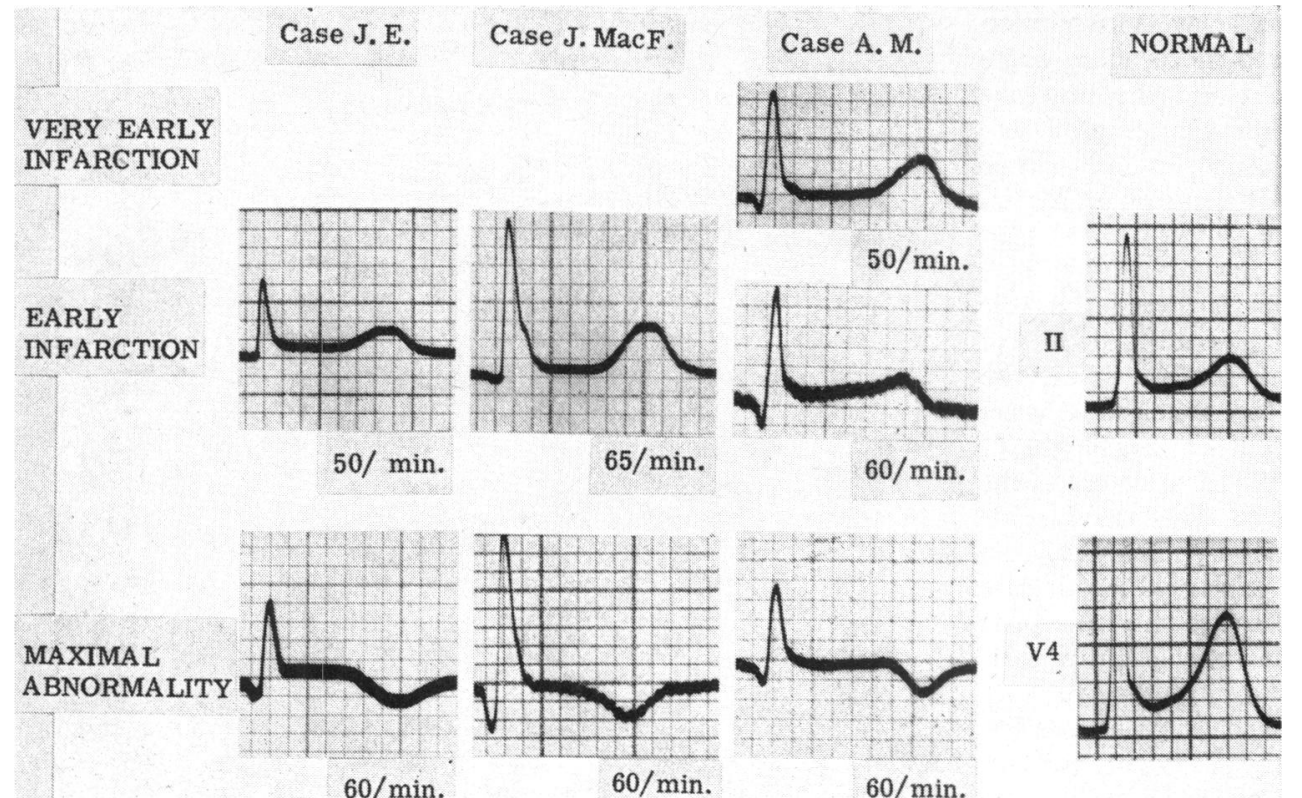

FIG. 4 Minor ST segment elevation - concave or 'saddle' type.

Case F. E., a man, aged 44 (lead aVF). Five days after the onset of cardiac pain there was approximately $0.5 \mathrm{~mm}$. ST elevation. A similar abnormality was seen in leads III and V6, with grade $2 S T$ depression in lead I. Seventeen days later, the $T$ wave had become inverted in aVF, low in II, and diphasic in V6.

Case F. MacF., a man, aged 70 (lead II). Twenty-four hours after the onset of cardiac pain, $0.5 \mathrm{~mm}$. ST elevation in leads II, III, and aVF were the only possible abnormal features noted in the cardiogram. Nine days later there were abnormal $Q$ waves and $T$ wave inversion in leads $I I$, $I I I$, and aVF. The history suggested an extension of the previous small infarct.

Case A. M., a man, aged 53 (lead I). Three days after the first attack of cardiac pain, and six hours after the second attack, the only possible abnormality was $0.3 \mathrm{~mm}$. concave ST elevation in lead I (full cardiogram, Fig. 2). On the following day, there was less concavity, and a reduction in $T$ wave voltage, with apparent shortening of the $Q T$ interval. Nine days later there was inversion of the $T$ wave in leads $I, a V L$, and $V_{4}$ to 6.

Case $R$. K., a man, aged 43 (leads II and V4). This man, with a clinically normal heart, had $I .0 \mathrm{~mm}$. concave ST elevation in II and I.5 mm. elevation in V4. A similar cardiogram had been recorded three years previously.

FIG. 5 Minor ST segment depression.

Case F. S., a man, aged 44. Infarction: Three days after onset of cardiac pain, the only

abnormality is grade 2 ST depression in lead II, and possibly in aVL. Infarction was confirmed by a rise of SGOT to 225 units, with normal SGPT. Recovery: Five days later, the cardiogram was within normal limits (see magnified cardiogram, Fig. 6.)

INFARCTION

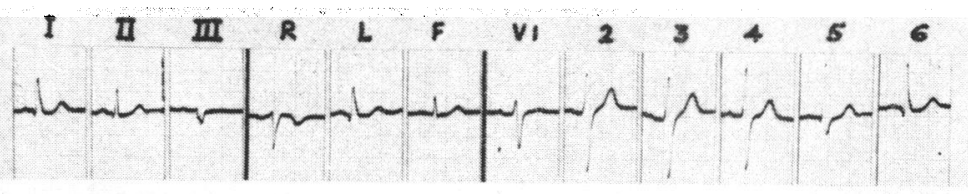

$85 / \min$.

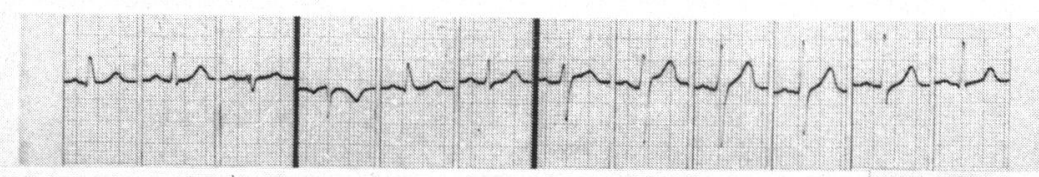

$70 / \mathrm{min}$. 
of the ST segment, with delayed inscription of the $T$ wave, making a more acute angle between the ST segment and the upstroke of the $T$ wave. In 7 , the abnormality was confined to the lateral leads, and was thus consistent with slight left ventricular hypertrophy.

Minor $T$ wave abnormalities were the sole abnormality in the initial cardiogram in five episodes. In each of these five cases, the abnormality lay in the fact that the $T$ wave was less than Io per cent of the height of the $R$ wave (Fig. 7 and 8 ). In three cases, the changes were confined to the lateral leads suggesting left ventricular hypertrophy. Another $\mathrm{T}$ wave deformity, observed in one case only, was an abrupt return to the isoelectric level (Fig. 9). This was so slight that it is classified among the borderline changes (see below); nevertheless, at the time it was recorded it was sufficiently suspicious to confirm the diagnosis of acute infarction, in spite of the fact that the remainder of the cardiogram was completely normal.

\section{(c) Borderline changes}

In seven episodes, the initial cardiogram showed only borderline changes. Three of these patients had $T$ waves which were low, but not low enough to be accepted as definite minor abnormalities. Another, referred to

FI G. 7 (Below)

Minor T wave abnormalities.

Case F. L., a woman, aged 53. Infarction:

Several weeks after the onset of crescendo angina, the only abnormality in the cardiogram was a low $T$ wave in lead $I$, and a suspiciously flat or diphasic $T$ wave in aVL. Recovery: 4 months later, the cardiogram was within normal limits.

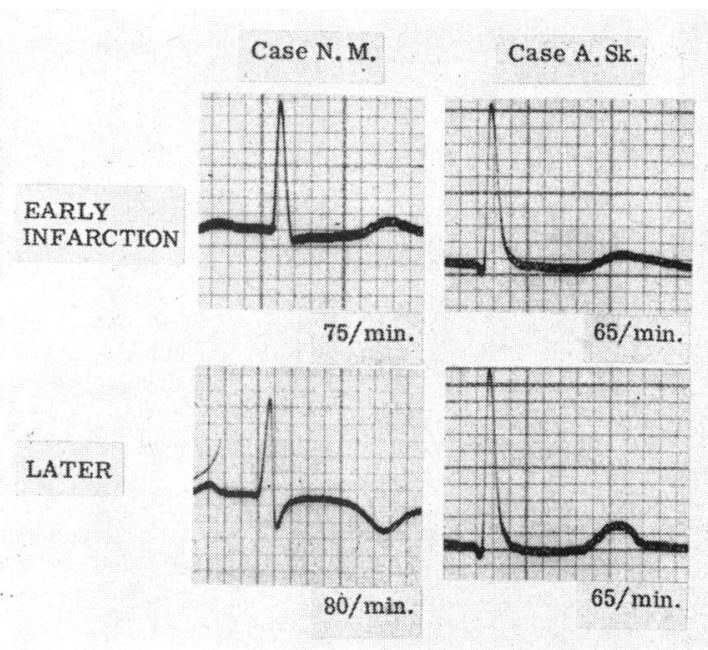

Case J.S.

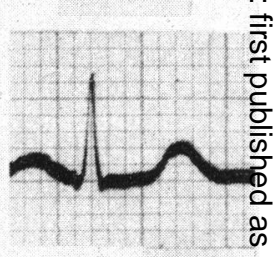

$85 / \mathrm{min} \cdot \overrightarrow{0}$

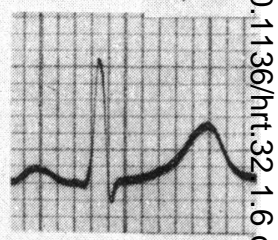

$70 / \mathrm{min}$. 음

FIG. 6

Minor ST segment depression.

Case N. M., a woman, aged 38 (lead I). Thirty

hours after the onset of cardiac pain, there is

grade $2 S T$ depression and probably some

reduction in $T$ wave voltage. A similar degree of

$S T$ depression was seen in leads $I I$, and $V 4$ to

V6. Three days later, the $T$ wave had become

inverted in leads $I, a V L$, and $V_{2}-V_{4}$.

Case A. Sk., a man, aged 58 (lead V5). This

patient gave a history of crescendo angina over

a period of several weeks or months. The

cardiogram showed grade $2 S T$ depression

associated with reduction in $T$ wave voltage in

leads I, V5, and V6. After four weeks, there

had been a partial recovery of $T$ wave voltage,

and a slight reduction in $S T$ depression.

Case F. S., a man, aged 44 (lead II). This

is the patient whose full cardiogram is shown in Fig. 5 .

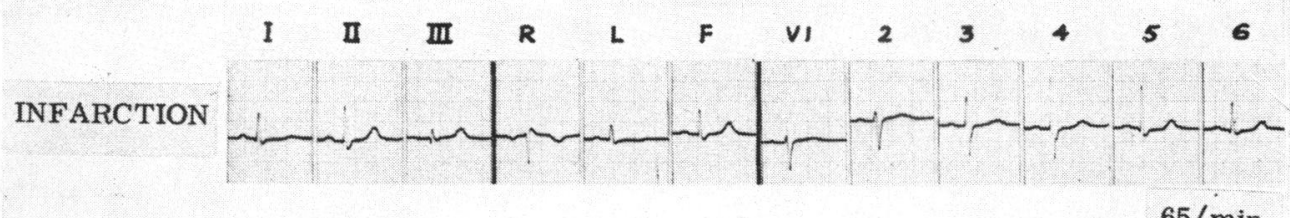

$65 / \mathrm{min}$.

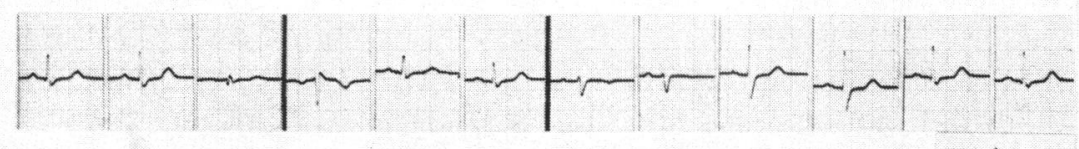

$70 / \mathrm{min}$. 
FIG. 8 Minor $\mathrm{T}$ wave abnormalities.

Case F. Mi., a man, aged 56 (lead II). Two days after the onset of cardiac pain, the main abnormality was a low $T$ wave in lead II associated with grade $2 S T$ depression. The $T$ wave was also flat in lead $a V F$ and there was grade I ST depression in V6. Four weeks later, there was a considerable increase in $T$ wave voltage in lead II, though the ST depression persisted. There was also residual grade $I$ $S T$ depression in leads $I$ and V6. Case W. D., a man, aged 53 (lead II). Four days after the onset of cardiac pain, the cardiogram showed no abnormality, though the $T$ waves in leads $I I$ and aVF were a little suspicious. Two months later, there was a striking increase in $T$ wave voltage in these leads.

above (Fig. 9), had a slight but definite abnormality in the form of the $T$ wave without reduction in voltage. One had a very minor degree of ST elevation in lead I, another conspicuous left axis deviation $(-20$ degrees) with a dominant $\mathrm{S}$ wave in lead II, and the last slight slurring or notching of the RS deflection (Fig. 10). In 5 of the 7 episodes, a subsequent cardiogram showed a major abnormality, and one was fatal; the remaining 2 showed no progression.

\section{(d) Normal cardiograms}

In Io episodes the initial cardiogram appeared to be within normal limits (Fig. II). In 9, major abnormalities developed subsequently, but in the other patient the cardiogram did not progress beyond borderline changes.

FIG. 9 Borderline $\mathrm{T}$ wave deformity. Case F. MacL., a man, aged 52 (lead VI). Infarction: 2 days after the onset of cardiac pain, the cardiogram was normal apart from the borderline deformity of the $T$ wave in $V I$ illustrated here. Note the somewhat abrupt return to the isoelectric level, compared with the appearance after recovery. Later: the following day, the $T$ wave in this lead was obviously diphasic. The $T$ wave had also become low in I and inverted in $V_{2}$ to $V_{4}$. Recovery: 3 months later, the cardiogram had returned to normal.
Case J. Mi.

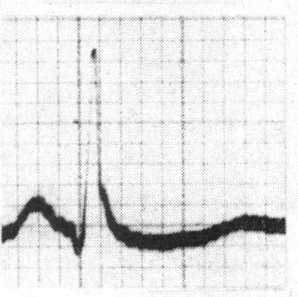

$60 / \mathrm{min}$

RECOVERY

INFARCTION

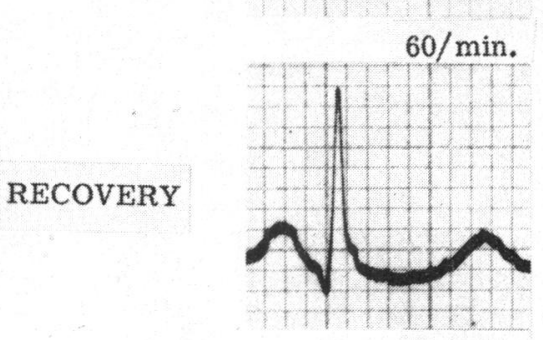

$65 / \mathrm{min}$.

Case W.D.

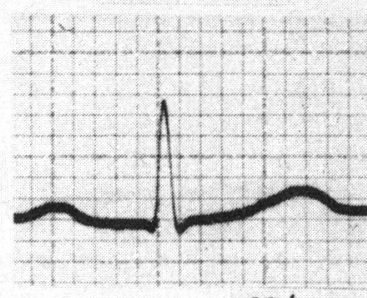

$90 / \mathrm{min}$

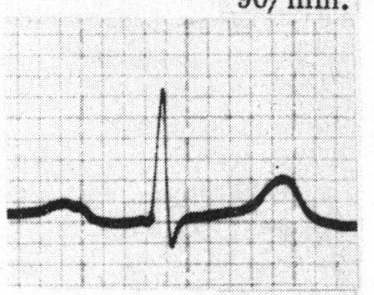

$85 / \mathrm{min}$.

\section{LATER}

EARLY

INFARCTION

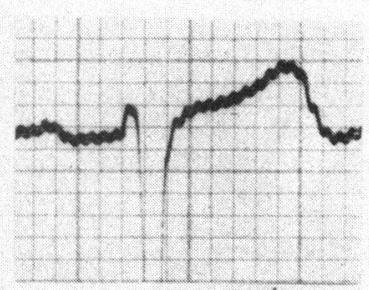

$60 / \mathrm{min}$.

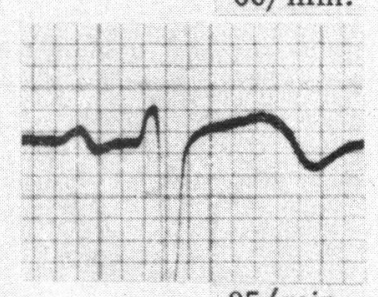

$85 / \mathrm{min}$.

\section{RECOVERY}

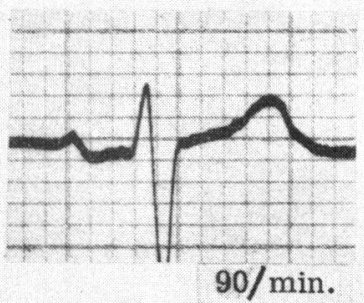




\section{Discussion}

This study has shown that in the early stages of slight or subacute myocardial infarction classical patterns such as major ST elevation, abnormal $Q$ waves, and obvious ST and $T$ wave changes are seen in only a minority of cases. On the other hand, minor abnormalities of the ST segment and $T$ wave are common, and borderline and even apparently normal tracings are not rare. It is therefore evident that special attention must be paid to the minor cardiographic changes found in early infarction, particularly the slight degrees of ST elevation which are strongly suggestive of an acute attack.

The attitude which condemns attention to minor cardiographic changes as tending to the production of unwarranted cardiac invalidism must be condemned. Though few, if any, of the minor abnormalities described in this paper are specific for coronary heart disease, nevertheless interpreted against the background of the clinical picture they may be of the utmost value in diagnosis. It is only if the cardiogram is interpreted without the full clinical evidence that it is dangerous (Short, 1969). Myocardial infarcts come in all shapes and sizes and the smallest ones never show major abnormalities. It is important to recognize that cases showing no definite abnormality in the initial stages are nevertheless potentially fatal (see Fig. IO).

It should not be necessary to point out that cardiograms showing ST depression (with or without reduction in $\mathrm{T}$ wave voltage) should not be dismissed, as they frequently are, with the report 'ischaemic changes only'; as if this abnormality was invariably a sign of a benign and transient disorder. Undoubtedly ST depression may indicate a transient ischaemia, but it frequently indicates subendocardial infarction, acute or chronic.

If minor abnormalities are to be recognized, the cardiogram must be of the highest technical quality, as Smith (1968) has emphasized. It is not always appreciated that a defective electrocardiograph machine may actually produce ST segment shifts (Berson and Pipberger, 1966).

The statement that the cardiogram may be normal at the onset of acute infarction demands further comment since it contradicts one of the emphatic conclusions of Evans (1965). Evans has repeatedly stated that the cardiogram is never normal in myocardial infarction, and indeed is invariably abnormal even before the patient develops a clinical episode of infarction. The only way in which these conflicting conclusions can be reconciled is by accepting that Evans finds abnormalities in tracings which the majority of cardiologists would accept as being within normal limits. The cardiograms regarded as normal in this series had gone through the sieve of the Minnesota Code, and then

FIG. Io Borderline RS deformity.

Case F. G., a man, aged 52. Infarction: 5 days after the onset of angina of effort, the cardiogram shows only notching or slurring of the $R S$ deflection in several leads. Later: 2 days later, the $T$ wave has become almost flat in I and V6, and inverted in $a V L$. Latest: II days later, the patient died suddenly from irreversible ventricular fibrillation.

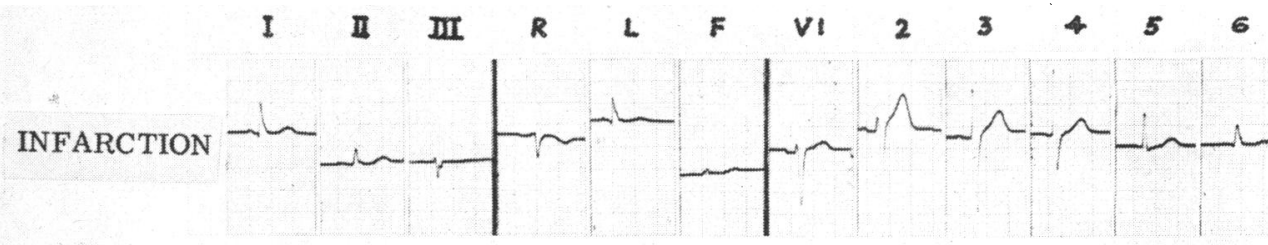

$85 / \min$.

LATER

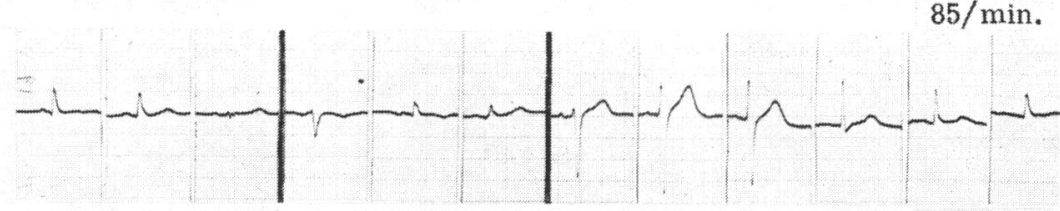

$65 / \min$

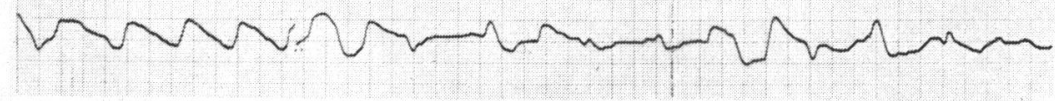



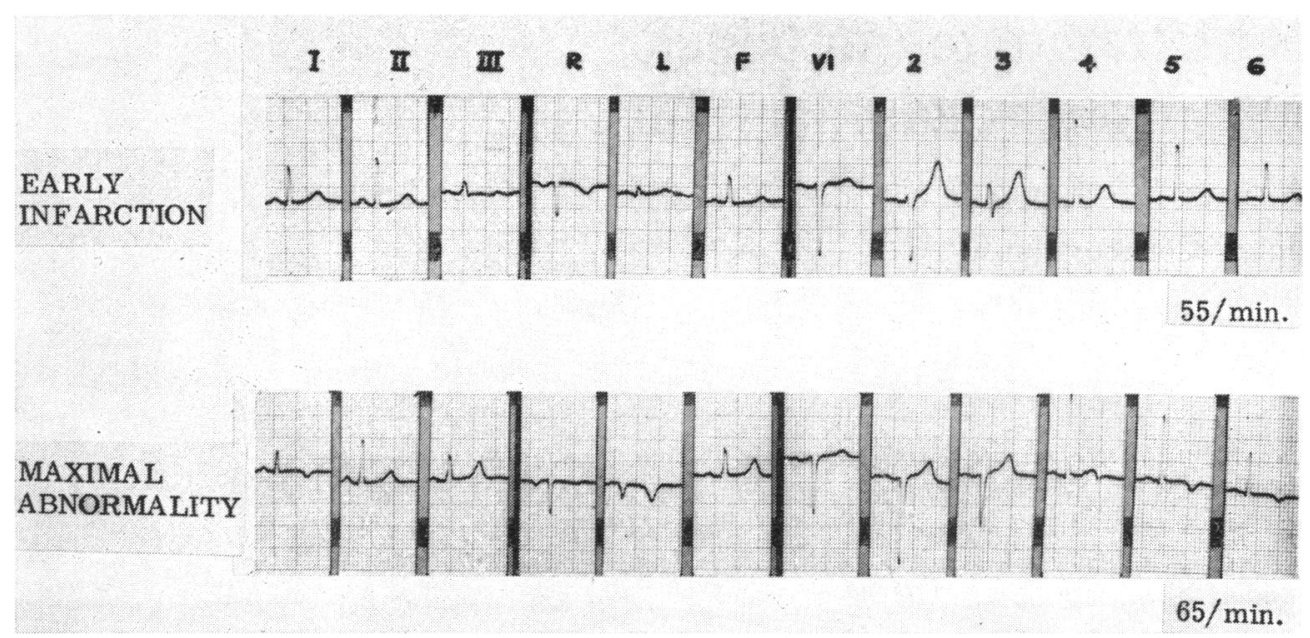

FIG. II Normal cardiogram.

Case R. T., a man, aged 35. Early infarction: II hours after the onset of cardiac pain, the cardiogram shows no abnormality. Maximal abnormality: By the following day, there was a reduction in $T$ wave voltage, and 2 days later $T$ wave inversion in leads $I, a V L$ and $V 5$, and V6.

through the fine sieve of Evans' minor cardiographic abnormalities as described and illustrated in his papers; and even after that a borderline group had been separated. The tracings which remained appeared to be as 'normal' as those recorded by the author on healthy medical students. It may, of course, be argued that a considerable proportion of these have myocardial infarction; but if so such infarction is of no practical importance.

It may be objected that there is no proof that all the episodes in this series were due to infarction. This must be conceded; for in slight and subacute coronary attacks death is fortunately infrequent and post-mortem confirmation correspondingly rare. It is conceivable that a few cases, such as the three miscellaneous patients without necropsy confirmation, might have been examples of coronary thrombosis without infarction; but if these and others were to be excluded, the findings would not be significantly affected. Even if the series were limited to those patients who at some time developed abnormal $Q$ waves, major ST elevation, classical serum enzyme changes, or in whom there was post-mortem confirmation, it would still remain true that the initial cardiogram in myocardial infarction frequently shows only minor abnormalities and is sometimes normal.

The author wishes to acknowledge his great debt to Dr. William Evans who has done so much to emphasize the importance of minor cardiographic abnormalities in coronary disease.

\section{References}

Berson, A. S., and Pipberger, H. V. (1966). The lowfrequency response of electrocardiographs, a frequent source of recording errors. American Heart fournal, 71, 779.

Blackburn, H., Keys, A., Simonson, E., Rautaharju, P., and Punsar, S. (1960). The electrocardiogram in population studies; a classification system. Circulation, 21, 1160.

Evans, W. (1965). Presaging cardiac pain. British Heart fournal, $27,856$.

-, and McRae, C. (1952). The lesser electrocardiographic signs of cardiac pain. British Heart fournal, 14, 429.

Short, D. (1969). An electrocardiogram reporting service: its role and its risks. British Heart fournal, 31, 531 .

Smith, K. S. (1968). Electrocardiography misused. British Heart fournal, 30, I. 